\title{
Tax Cuts, Venture Capital, and Long-Term Growth
}

Juan M. Sánchez, ${ }^{1}$ Assistant Vice President and Economist

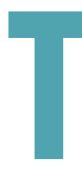
he effect of lower taxation on growth was a central argument in favor of the Tax Cuts and Jobs Act of 2017. Barro and Furman (2018) predicted that the act would boost gross domestic product (GDP) by 1.1 percentage points per year in 2018 and in $2019^{2}$ but that most of the boost will disappear quickly, decreasing to only 0.2 percentage points annually after 10 years. In this essay, I argue that data on innovation and activities funded by venture-capital (VC) show the permanent impact of tax cuts on growth-given that the tax cuts remain. Most of the analysis will draw from my recent working paper "Financing Ventures: Some Macroeconomics," written with Jeremy Greenwood and Pengfei Han. ${ }^{3}$

The rise in venture capital investment suggests the 2017 tax cuts will increase economic growth through more-profitable investment in innovation.

The Tax Cuts and Jobs Act made two significant changes to business tax law. First, it lowered the federal tax rate by up to 14 percentage points for businesses, with varying rate changes depending on the form of incorporation. Second, it allowed companies to deduct the full cost of their investments in anything other than structures from current taxes.

Our paper analyzes the effect of tax rate changes in a model in which VC-financed innovation drives economic growth - with the aim of explaining real-world funding for leading firms in sectors such as information and communication technology, biotechnology, and services, where VC funding is particularly important for startups.

In the United States, entrepreneurs funded with VC pay a 15 percent tax rate on their gains after an initial public offering or acquisition. In other countries, especially in Europe, similar entrepreneurs would pay much higher tax rates. Our model predicts that increasing the U.S. tax rate from 15 percent to 35 percent would decrease growth by 0.11 percentage points for as long as the change persists. This seemingly small growth change is very important, as it has a large cumulative effect on the level of output over time.

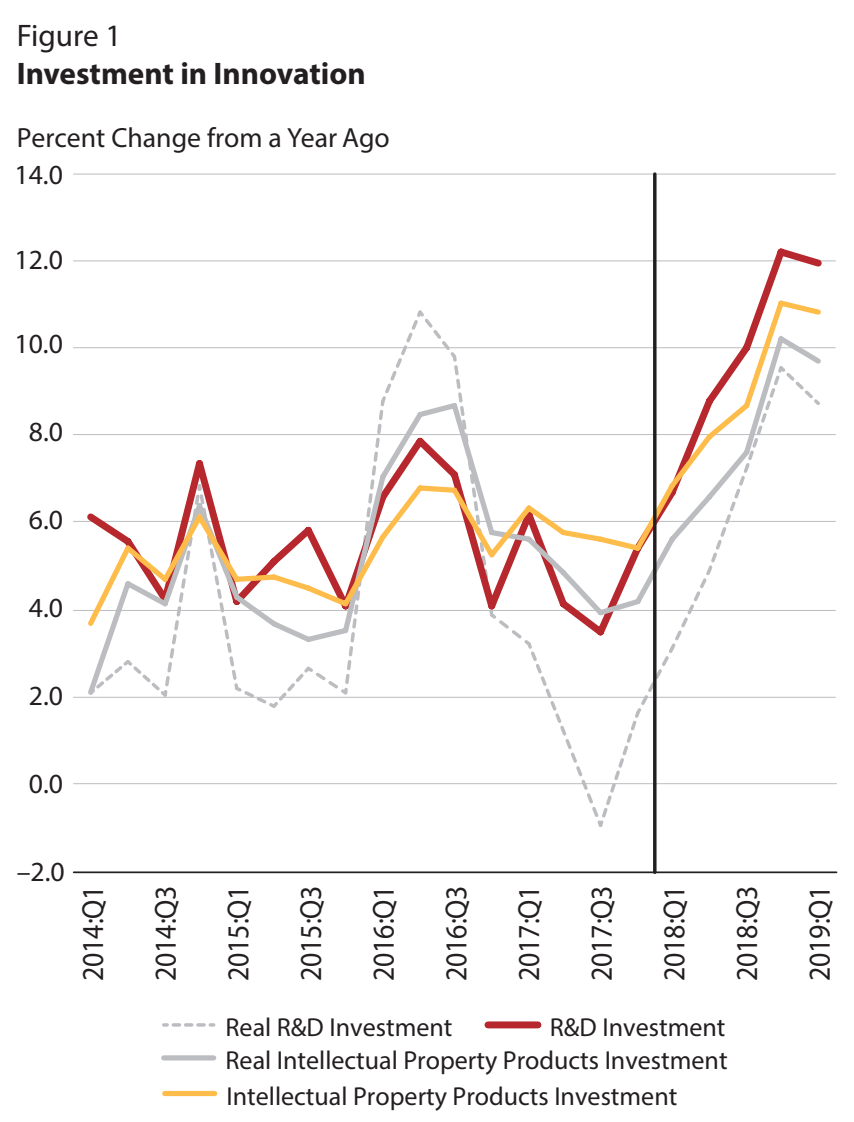

NOTE: The vertical line indicates the introduction of the Tax Cuts and Jobs Act. SOURCE: Bureau of Economic Analysis.

In our model, growth responds to taxes because tax cuts encourage expenditures on innovation. I expect a similar effect from the changes made by the Tax Cuts and Jobs Act because owners of new ideas will be able to keep a larger share of the profits. In national data, innovation is measured by investments in intellectual property products and one of its main components, research and development (R\&D). Figure 1 plots the year-over-year change in these variables since 2014 and suggests that the act propelled some of the fastest growth in R\&D spending since the recovery from the Great Recession. ${ }^{4}$ The growth rate in R\&D investment (red line) has been on average 9.9 percent since the act; the average from 1995 to 2017 was only 6.1 percent. The dotcom boom (1995-2000) is the only other period with similar growth in R\&D. 
Figure 2

\section{Growth of VC Investment by Sector}

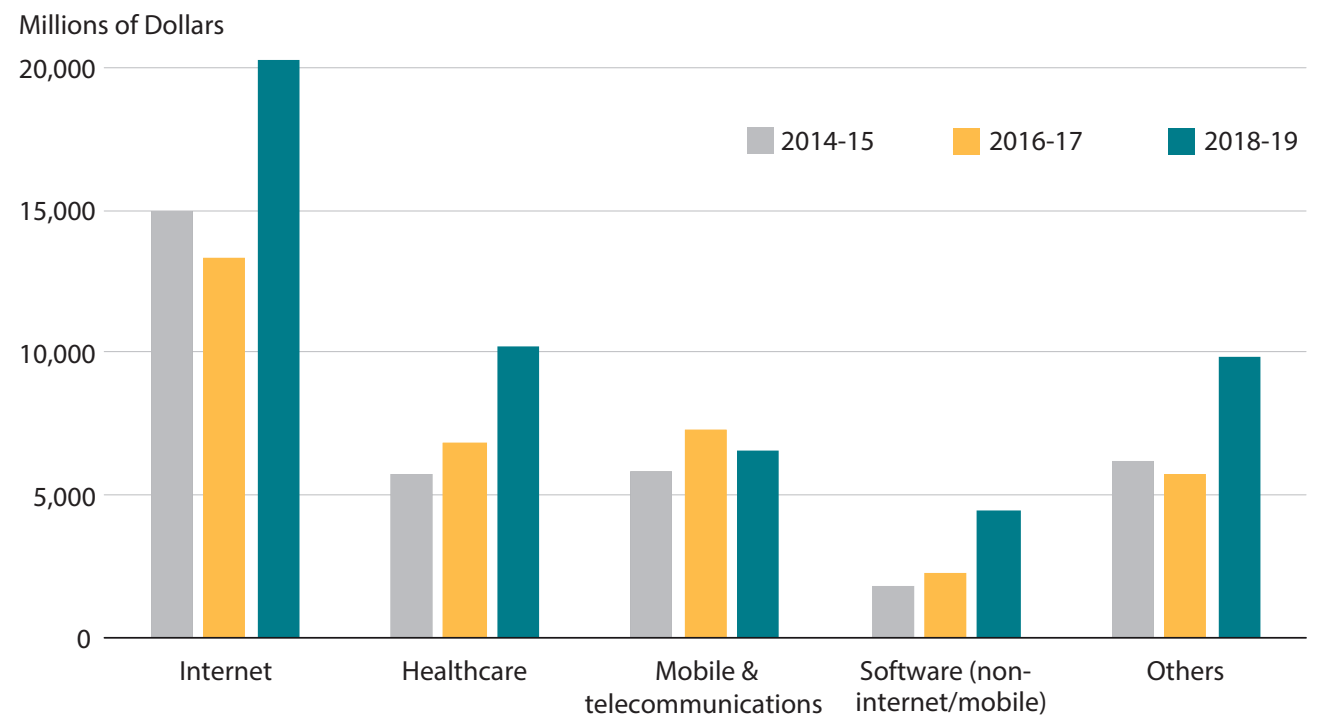

SOURCE: PwC/CBInsights MoneyTree ${ }^{\mathrm{TM}}$ data explorer.

Another way to analyze the effect of the act on long-term growth is to look at data on $\mathrm{VC}$ investment. The PwC/CB Insights MoneyTree ${ }^{\mathrm{mat}}$ Report provides data on VC investment. Between 2007 and 2017, the average yearly growth rate of VC investment was 11.2 percent, but it grew by 51.2 percent between 2017 and 2018. That is, VC investment growth was 40 percentage points larger in 2018 than what it was previously.

Figure 2 shows the levels of VC investment by sector for the years 2014-15, 2016-17, and 2018-19.5 The key is to compare the changes in VC investment after the tax cuts (2018-19 vs. 2016-17) taking into account the previous trend (2016-17 vs. 2014-15). VC investment grew faster after the act. The difference in the dollar amounts is largest for sectors that receive VC investment: internet, healthcare, and software. But there are also significant differences for other sectors that do not receive much VC investment, such as automotive and transportation.

In sum, the evidence suggests that both innovation and VC investment increased significantly after the Tax Cuts and Jobs Act. The level of innovation and VC investment in 2018 and the first half of 2019 should support increased growth rates in the next years.

\section{Notes}

1 The author thanks Ryan Mather for helping in the preparation of this essay.

2 In 2018, the prediction was mostly correct, as noted in Barro (2019).

3 Greenwood, Han, and Sánchez (2018).

4 For similar findings for previous periods, see Akcigit et al. (2018).

5 To make the figures comparable in terms of seasonality with the data available for 2019, I take the average across years of VC investment during the first half of each year.

\section{References}

Akcigit, Ufuk; Grigsby, John; Nicholas, Tom and Stantcheva, Stefanie. "Taxation and Innovation in the 20th Century." NBER Working Paper No. 24982, National Bureau of Economic Research, October 2018.

Barro, Robert J. "My Best Forecast Year Ever." Project Syndicate, April 29, 2019; https://www.project-syndicate.org/commentary/trump-tax-cuts-boost-economic-growth-by-robert-j-barro-2019-04.

Barro, Robert, and Furman, Jason. “The Macroeconomic Effects of the 2017 Tax Reform." Conference draft, Brookings Paper on Economic Activity, March 2018.

Greenwood, Jeremy; Han, Pengfei and Sánchez, Juan M. "Financing Ventures: Some Macroeconomics." Working Paper 2017-035, Federal Reserve Bank of St. Louis, July 2018; https://doi.org/10.20955/wp.2017.035. 